\section{Dollar Spot Severity as Influenced by Fungicide Mode of Activity and Spray Nozzle}

\author{
John E. Kaminski ${ }^{1}$ \\ Department of Crop and Soil Sciences, The Pennsylvania State University, \\ University Park, PA 16802
}

\section{Michael A. Fidanza \\ Division of Science, Berks Campus, The Pennsylvania State University, Reading, PA 19610}

Additional index words. Agrostis stolonifera, Poa annua, application technology, water volume, pesticide, pesticide application technology, turf, turfgrass

\begin{abstract}
Dollar spot, caused by Sclerotinia homoeocarpa, is a severe disease of highly maintained turfgrass. Improving the efficacy of fungicides when applied in relatively low water volumes may be possible through the optimization of nozzle selection. The objectives of this research were to evaluate fungicide efficacy when delivered through five different nozzle types and to elucidate any potential interactions between fungicide mode of activity and nozzle type. Research was conducted at four locations in Pennsylvania and Connecticut in 2005. Chlorothalonil (contact mode of activity) and propiconazole (acropetal penetrant mode of activity) were applied alone or tank-mixed and delivered through five different nozzles. At all sites, no fungicide-by-nozzle interactions were observed, and dollar spot suppression was generally greatest when fungicides were tankmixed. The TurfJet 1/4TTJ04 nozzle generally provided the poorest level of control when compared with all other nozzles (i.e., Air Induction AI11004, Turbo TeeJet TT11003, and XR TeeJet XR11003 or XR11004). Although the impact of nozzle type was not as pronounced under low to moderate disease pressure, nozzles that produce fine to coarse water droplets (i.e., Turbo TeeJet or XR TeeJet) or the Air Induction (AI) nozzle were associated with the best suppression under severe dollar spot pressure. Despite producing a very coarse droplet, the AI nozzle also facilitated excellent suppression of dollar spot under severe disease pressure. The use of AI-type nozzles may improve the efficacy of fungicides used to control foliar diseases while at the same time minimize the potential for drift to off-site targets.
\end{abstract}

Dollar spot (Sclerotinia homoeocarpa F.T. Bennett) is perhaps the most chronic and problematic disease of golf course turf throughout the United States (Couch, 1995; Dernoeden, 2000). The disease can be particularly damaging to creeping bentgrass

Received for publication 12 June 2009. Accepted for publication 10 Aug. 2009.

Mention of trademark, proprietary product, or vendor does not constitute a guarantee or warranty of the product by The Pennsylvania State University or the authors and does not imply its approval to the exclusion of other products that also may be suitable.

We are grateful to Dr. M. Agnew and Dr. D. Shepard (Syngenta Professional Products, Greensboro, NC), the New England Regional Turfgrass Foundation, the Pennsylvania Turfgrass Council, and the United States Golf Association for the financial assistance provided to support this research. The authors also appreciate all golf courses and golf course superintendents for cooperating with this research, to T. Reed (Midwest Technologies, Dillsburg, PA) for providing nozzles, and J. Gregos (GEC Turf Consulting, Pittsburgh, PA) and A. Putman (former graduate student at the University of Connecticut, Storrs, CT) for their assistance. ${ }^{1}$ To whom reprint requests should be addressed; e-mailkaminski@psu.edu.
(Agrostis stolonifera L.) and annual bluegrass (Poa annua L.) greens, tees, and fairways (Smiley et al., 2005; Watschke et al., 1994). Due to the severity and destructive nature of dollar spot in high-value turf, fungicides are considered a key component in most management strategies or programs (Dernoeden, 2000; Fidanza et al., 2006).

Improved disease suppression in various crops has been attributed to adjustments in fungicide application techniques, including water-carrier volume, spray pattern, and water-droplet size (Armstrong-Cho et al., 2008; Chapple et al., 1997; Jensen et al., 2001; Lesnik et al., 2005). In creeping bentgrass, Couch (1985) reported that a localized penetrant fungicide dispersed in a flat-fan spray pattern and producing small water droplets provided better dollar spot control when compared with the same fungicide applied with a hollow-cone nozzle that produced very large droplets (Couch, 1985). Improved suppression of dollar spot in creeping bentgrass from nozzles that produce smaller droplet sizes has also been recently reported with the use of contact fungicides (Fidanza et al., 2009b; Kaminski et al., 2006; Vincelli and Dixon, 2007). Vincelli and Dixon (2007) attributed improved suppression of dollar spot to nozzles that resulted in increased spray coverage. Couch (1985) showed that contact fungicides were most effective at a lower water volume (e.g., $407 \mathrm{~L} \cdot \mathrm{ha}^{-1}$ ) and systemic-type fungicides were more effective at higher water volume (e.g., $\left.814 \mathrm{~L} \cdot \mathrm{ha}^{-1}\right)$. However, turfgrass managers often apply tankmixes of fungicides with varying modes of activity (e.g., contact or systemic-type categorized as acropetal or localized penetrant, etc.) in lower water volumes in the interest of saving labor expenses and time (Agnew and Fidanza, 2007).

Fungicide programs are commonly recommended to manage diseases in turf maintained as golf course greens, tees, and fairways (Agnew, 2007), and optimum fungicide delivery has become a critical factor to ensure a successful disease control outcome (Agnew and Fidanza, 2007; Couch, 1985; Kaminski et al., 2006; Shepard et al., 2006). In recent years, many turfgrass practitioners have reported a reduction in efficacy and length of control associated with fungicides used to manage dollar spot (Fidanza et al., 2007; Shepard et al., 2006). Possible reasons for this reduction include variation in product application rates and timings, differences in application techniques and procedures, and resistance issues attributed to continuous use of the same fungicide product or fungicide biochemical mode of action (Doney and Vincelli, 1994; Golembiewski et al., 1995; Zontek, 2003).

Several nozzle-types are available in the crop protection market, and these nozzles produce a range of water droplet sizes (Matthews, 1999; Wolf et al., 2002). Many of these nozzles were recently introduced into the green industry and specialty crop markets (Fidanza et al., 2007; Shepard et al., 2006). Hence, the overall purpose of this study was to examine the impact of nozzle-type and fungicide mode of activity on fungicide performance for dollar spot control in creeping bentgrass. The specific objectives were to evaluate fungicide efficacy when delivered through five different nozzle types and to elucidate any interactions among nozzle type and fungicide mode of activity.

\section{Materials and Methods}

This research consisted of four identical field studies conducted in two locations in Connecticut and Pennsylvania in 2005. In Connecticut, field studies were conducted on golf course fairways at The Country Club of Farmington (CCF; Farmington, CT) and Stanley Golf Club (SGC; New Britain, CT). The SGC site consisted of a mixed stand of creeping bentgrass (unknown cultivar) and annual bluegrass maintained at a height of $1.9 \mathrm{~cm}$. Soil was a Ludlow (coarse-loamy, mixed, semiactive, mesic Aquic Dystrudepts) silt loam with a $\mathrm{pH}$ of 5.7 and $9.2 \%$ organic matter. The CCF site was predominantly 'Penncross' creeping bentgrass with $<10 \%$ annual bluegrass grown on a Rippowan (coarse-loamy, mixed, superactive, nonacid, mesic Fluvaquentic Endoaquepts) fine sandy loam with a $\mathrm{pH}$ of 5.3 and $3.4 \%$ organic 
matter and mowed to a height of $1.3 \mathrm{~cm}$. Urea was applied to the CCF site at a rate to deliver $\mathrm{N}$ at $73 \mathrm{~kg} \cdot \mathrm{ha}^{-1}$ in the spring before treatment initiation. No fertilizer was applied to the SGC site during the study. Plots measured $1.5 \mathrm{~m} \times 4.5 \mathrm{~m}$ and were arranged as a $3 \times 5$ factorial design with three (CCF) or four (SGC) replications. In addition, a single untreated control was included within the study to assess the impact had fungicides not been applied.

In Pennsylvania, two field studies were conducted on a golf course fairway (Royal Oaks Golf Course; ROGC; Lebanon, PA) and a driving range (Bellewood Golf Club; BGC; North Coventry, PA) maintained as a fairway. The ROGC and BGC site consisted of a monostand of creeping bentgrass established to cultivars 'Princeville' and 'PennTrio', respectively. Soil at ROGC was a Clarksburg (fine-loamy, mixed, active, mesic Typic Fragiudalfs) clay loam with a $\mathrm{pH}$ of 6.8 and $4.0 \%$ organic matter. In the early spring, a slow-release fertilizer was applied at ROGC at an amount of $36 \mathrm{~kg} \mathrm{~N} \cdot \mathrm{ha}^{-1}$. At the BGC site, soil was a Readington (fine-loamy, mixed, semiactive, mesic Typic Fragiudalfs) silt loam with a $\mathrm{pH}$ of 6.6 and $2.0 \%$ organic matter. No fertilizer was applied to the BGC test site in anticipation of this experiment. Both sites were mowed to a height of $1.1 \mathrm{~cm}$ with a reel mower, and plots measured $1.5 \times$ $3 \mathrm{~m}$ with three replications arranged similar to studies in Connecticut.

At all four locations, fungicide treatments were applied using one of five flat-fan nozzle types designed to distribute varying water droplet sizes. The nozzles were selected to produce droplet sizes that were classified as extremely coarse $(\geq 450 \mu \mathrm{m}$ in diameter; TurfJet 1/4TTJ04), very coarse (375-450 $\mu \mathrm{m}$ in diameter; Air Induction TeeJet AI11004), coarse (250-375 $\mu \mathrm{m}$ in diameter; TurboTeeJet TT11003), medium (175-250 $\mu \mathrm{m}$ in diameter; XRTeeJet XR11004), and fine $(100-175 \mu \mathrm{m}$ in diameter; XR TeeJet XR11003) (Hewitt et al., 1996). The TurfJet and XRTeeJet nozzles produce a standard pattern flat fan pattern with varying size water droplets. The Air Induction and TurboTeeJet nozzles, however, produce relatively large air-filled drops through the use of a Venturi air aspirator or through a large, rounded internal passage, respectively. These nozzles are commonly promoted for use on golf courses, and are manufactured by Spraying Systems (Wheaton, IL). All nozzles were used to apply fungicides with an acropetal penetrant mode of activity (propiconazole; Banner MAXX; Syngenta Professional Products, Greensboro, NC), a contact mode of activity (chlorothalonil; Daconil; Syngenta Professional Products, Greensboro, NC), and a tank-mix of the two fungicides. Chlorothalonil (4.56 $\mathrm{kg}$ ai/ha) and propiconazole $(0.236 \mathrm{~kg}$ ai $/ \mathrm{ha})$ were applied at the low recommended label use rate for the preventive control of dollar spot.

Treatments in Connecticut were applied with a $\mathrm{CO}_{2}$-pressurized $(275 \mathrm{kPa})$ backpack sprayer and in Pennsylvania with a Gregson-
Clark Spreader Mate (Gregson-Clark, Le Roy, NY). Both application mechanisms were outfitted with a spray boom containing three nozzles spaced $48 \mathrm{~cm}$ on center and calibrated to deliver water at $407 \mathrm{~L} \cdot \mathrm{ha}^{-1}$, which is a standard volume used for golf course fairways (Agnew and Fidanza, 2007). To account for variation in output from each nozzle, walking speed was adjusted to 3.2 or $4.5 \mathrm{~km} \cdot \mathrm{h}^{-1}$ using a metronome (KORG USA, Inc.; Melville, NY). All treatments were applied on $\approx 14$-d intervals and all application dates are footnoted in the data tables.

Disease assessment and statistical analyses. To assess dollar spot incidence, the numbers of dollar spot infection centers per plot (IC) were counted throughout the study. To reduce the impact of an edge effect, a $25.4-\mathrm{cm}$ border was excluded from each plot during the rating. A threshold of $\leq 10$ ICs per plot was considered an acceptable amount of dollar spot activity for fairway turf in these studies. Based on the plot of the residuals, all IC data were square root transformed before analyses. To assess the overall impact of disease development throughout the study, the area under the disease progress curve (AUDPC) was determined. The AUDPC values were calculated using the formula: $\left[\left(\mathrm{y}_{i}+\mathrm{y}_{i}+1\right) / 2\right]\left(\mathrm{t}_{i}+1-\mathrm{t}_{i}\right)$, where $i=1,2,3 \ldots \mathrm{n}-1$, where $\mathrm{y}_{i}$ is the number of IC per plot and $\mathrm{t}_{i}$ is the time of the $i$ th rating (Campbell and Madden, 1990). Data were subjected to analysis of variance and means were separated using the Fisher's protected least significant difference test $(P \leq 0.05)$. In addition to treatment effects, treatments were further subjected to preplanned single degree-of-freedom orthogonal contrasts (Mead et al., 2003).

\section{Results and Discussion}

Data for each site were analyzed independently due to variations in application and rating dates, disease pressure, and turfgrass species. At all locations, examination of the data revealed no significant interactions among fungicide or nozzle-type (Tables 14). Therefore, the main effects of fungicide and nozzle type were examined in detail for each location when determined to be statistically significant.

Connecticut: Stanley Golf Club. Disease pressure at SGC was considered severe. At SGC, no dollar spot symptoms were visible when treatments were initiated on 27 May. Over the entire study, IC within the untreated control plots ranged from 54 to 329 (Table 1). On the first rating date (10 June), an average of 57 ICs was present within the untreated control plot. The main effect of fungicide was significant on all rating dates, and plots treated with chlorothalonil + propiconazole exhibited the least dollar spot when compared with each fungicide applied alone. The tank-mix combination provided near complete suppression $(\leq 1$ IC) of dollar spot between 10 June and 1 July. When plots were rated on 19 July ( $\approx 4$ weeks after treatment), the tank-mix combination continued to pro- vide suppression of dollar spot when compared with each individual fungicide, but no treatments were considered acceptable. The main effect of nozzle-type was significant on all dates until 19 July. The greatest level of dollar spot suppression was achieved in plots receiving fungicides applied with AI11004, XR11004, or XR11003 nozzles. Turfgrass within plots receiving fungicides applied with the 1/4TTJ04 nozzles had the greatest number of IC throughout the study. When disease pressure increased in early July, unacceptable dollar spot suppression was observed within fungicide-treated plots applied with 1/4TTJ04 and TT11003 nozzles. When compared with the untreated control plots, all nozzles and fungicides resulted in an $83 \%$ to $98 \%$ reduction in dollar spot during the treatment period. Under the high seasonal pressure observed at SGC, AUDPC values indicated that the tank-mix combination applied from XR11004, XR11003, or AI11004 nozzles provided the greatest suppression of dollar spot (Figs. 1 and 2).

Connecticut: Country Club of Farmington. Dollar spot was low throughout the study period and a total of 26 IC was observed in the untreated plots when disease activity peaked on 19 July (25 DAT) (Table 2). During this period of low disease pressure, there were no significant fungicide $\times$ nozzle interactions and the main effect of fungicide

Table 1. Dollar spot (Sclerotinia homoeocarpa) infection centers as influenced by chlorothalonil, propiconazole, and a tank-mix applied using five different nozzles at Stanley Golf Club 2005 .

\begin{tabular}{|c|c|c|c|c|}
\hline \multirow[b]{3}{*}{ Treatment $^{\mathrm{w}}$} & \multicolumn{4}{|c|}{ Dollar spot (no.) ${ }^{\mathrm{v}}$} \\
\hline & 10 & 24 & 1 & 19 \\
\hline & June & June & July & July \\
\hline \multicolumn{5}{|l|}{ Fungicide } \\
\hline Chlorothalonil & $9 \mathrm{a}^{\mathrm{x}}$ & $4 \mathrm{a}$ & $13 \mathrm{~b}$ & $148 \mathrm{a}$ \\
\hline Propiconazole & $14 \mathrm{a}$ & $6 a$ & $18 \mathrm{a}$ & $147 \mathrm{a}$ \\
\hline $\begin{array}{l}\text { Chlorothalonil } \\
+ \text { propiconazole }\end{array}$ & $1 \mathrm{~b}$ & $0 \mathrm{~b}$ & $1 \mathrm{c}$ & $94 \mathrm{~b}$ \\
\hline \multicolumn{5}{|l|}{ Nozzle (droplet size) $)^{y}$} \\
\hline TTJ1104 (EC) & $13 \mathrm{a}$ & $7 \mathrm{a}$ & $24 \mathrm{a}$ & 148 \\
\hline AI11004 (VC) & $3 \mathrm{~b}$ & $1 \mathrm{~b}$ & $3 \mathrm{c}$ & 120 \\
\hline TT11003 (C) & $13 \mathrm{a}$ & $6 a$ & $11 \mathrm{~b}$ & 140 \\
\hline XR11004 (M) & $6 \mathrm{~b}$ & $3 \mathrm{~b}$ & $9 \mathrm{bc}$ & 122 \\
\hline XR11003 (F) & $5 \mathrm{~b}$ & $2 b$ & $5 \mathrm{c}$ & 117 \\
\hline Untreated $^{\mathrm{x}}$ & 57 & 54 & 145 & 329 \\
\hline \multicolumn{5}{|l|}{ Probability } \\
\hline Fungicide & $* * *^{\mathrm{z}}$ & $* * *$ & $* * *$ & $* * *$ \\
\hline Nozzle & $* * *$ & $* *$ & $* * *$ & NS \\
\hline Fungicide $\times$ nozzle & NS & NS & NS & NS \\
\hline
\end{tabular}

z**, $* * *$ indicates significance at $\leq 0.01$ and $\leq 0.001$, respectively. $\mathrm{NS}=$ not significant.

${ }^{\mathrm{y}}$ Droplet sizes are as follows: $\mathrm{EC}=$ extremely coarse, $\mathrm{VC}=$ very coarse, $\mathrm{C}=$ coarse, $\mathrm{M}=$ medium, and $\mathrm{F}=$ fine.

${ }^{x}$ Means for each main factor and within each column followed by the same letter are not significantly different $(P \leq 0.05)$ according to Fisher's protected least significant difference test. Dollar spot levels within untreated plots are shown for comparison proposes but are not included in the statistical analysis.

wTreatments were applied on 27 May, and 10 and 24 June.

Dollar spot was rated by counting the number of infection centers per plot (4 sq m). 


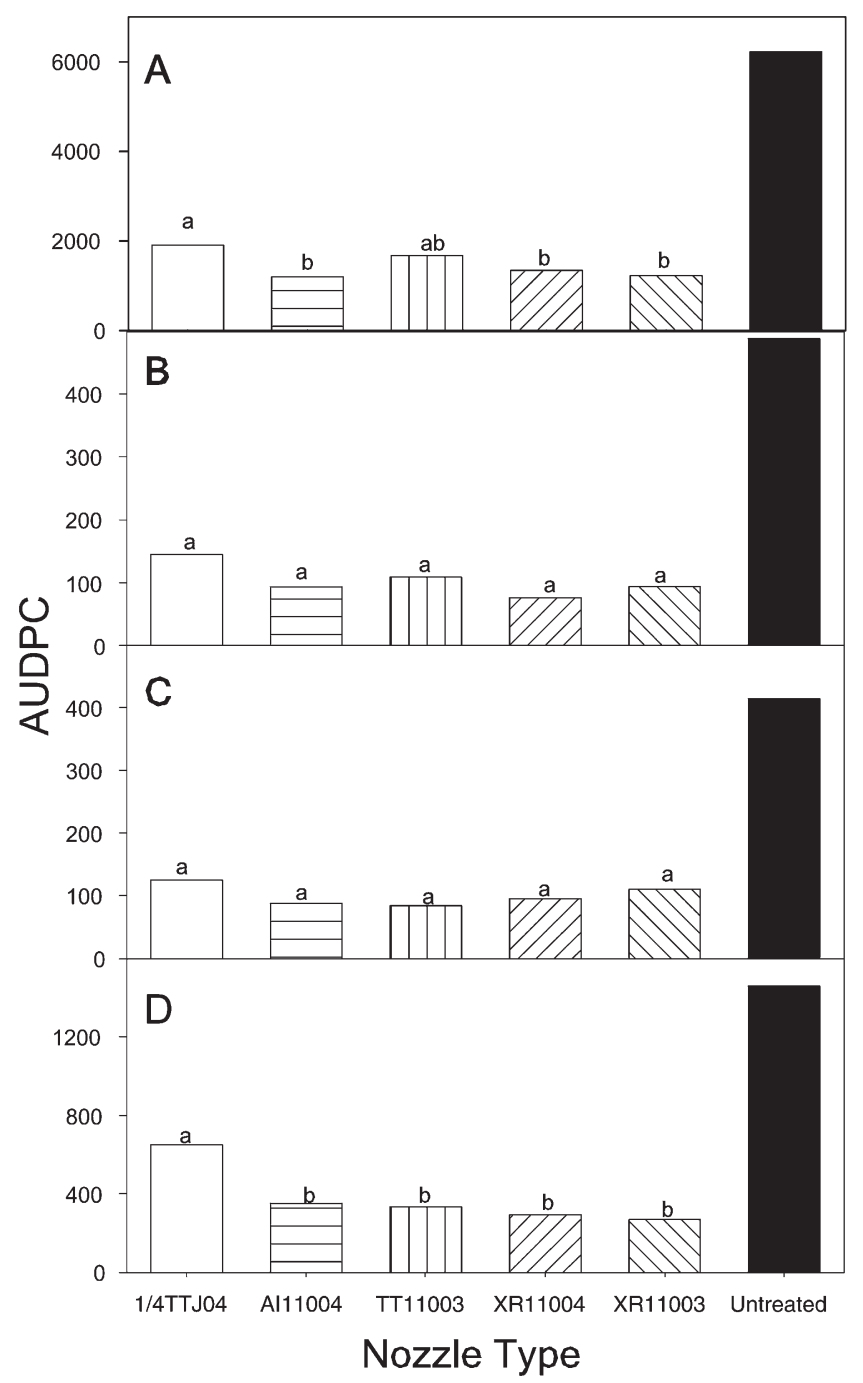

Fig. 1. Area under the disease progress curve (AUDPC) for dollar spot infection centers at four locations as influenced by nozzle type. Nozzle type (TurfJet 1/4TTJ04, extremely coarse water droplet $\geq 450 \mu \mathrm{m}$ in diameter; Air Induction TeeJet AI11004, very coarse water droplet 375 to $450 \mu \mathrm{m}$ in diameter; TurboTeeJet TT11003, coarse water droplet 250 to $375 \mu \mathrm{m}$ in diameter; XRTeeJet XR11004, medium water droplet 175 to $250 \mu \mathrm{m}$ in diameter; and XR11003, fine water droplet 100 to $175 \mu \mathrm{m}$ in diameter) from Stanley Golf Club (A), Country Club of Farmington (B), Bellewood Golf Club (C), and Royal Oaks Golf Course (D). Means followed by the same letter are not different according to Fisher's protected least significant difference test at $P \leq 0.05$. Dollar spot levels in untreated plots are shown for comparison proposes but are not included in the statistical analysis.

AI11004 $=$ TT11003 $>$ 1/4TTJ04 nozzles. On this final rating date, only those fungicides applied through the XR nozzles provided acceptable control. Over the course of the study, AUDPC values indicated a significant main effect of fungicide and nozzle (Figs. 1 and 2). When applied on an approximate 14day interval, all nozzles except 1/4TTJ04 facilitated a similar amount of disease reduction (Fig. 1), and the greatest suppression of dollar spot was achieved when chlorothalonil and propiconazole were tank-mixed (Fig. 2).

The overall goal of this study was to determine dollar spot control from two fungicides with different modes of activity when applied through five different nozzles. The spray nozzle is the last piece of equipment that a pesticide comes into contact with and adjustments to the spray droplet formation and size likely facilitates better coverage and improved protection (Couch, 1985; Fidanza et al., 2009a, b; Shepard et al., 2006; Vincelli and Dixon, 2007). Regardless of the nozzle type evaluated in this study, all fungicides reduced dollar spot when compared with the untreated control. The 1/4TTJ04 nozzle produced the largest water droplet size and provided highly variable and often times poor control of dollar spot, regardless of fungicide mode of activity. Although fungicides used to control dollar spot may be more efficacious when applied using a nozzle that produces fine to coarse droplet sizes, the potential for spray drift and/or negative off-target environmental impacts may increase (Hewitt et al., 1996). The use of nozzles such as the Air Induction and Turbo TeeJet offer driftreducing advantages when compared with the standard extended range tips and also

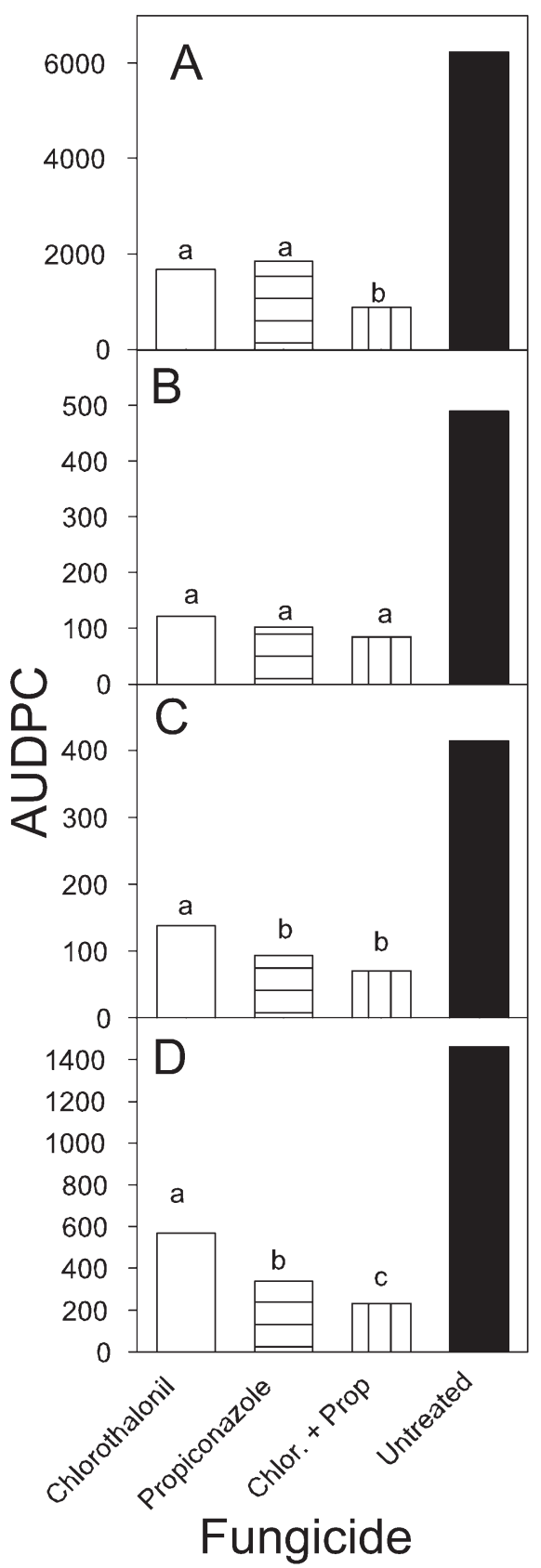

Fig. 2. Area under the disease progress curve (AUDPC) for dollar spot infection centers at four locations as influenced by fungicides. Fungicides included chlorothalonil (Chlor.;

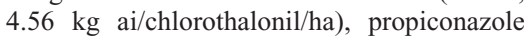
(Prop.; $0.236 \mathrm{~kg}$ ai $/ \mathrm{ha}$ ), and a tank-mix of the two. Data were pooled across five nozzle types. Data represent seasonal dollar spot infection center ratings from Stanley Golf Club (A), Country Club of Farmington (B), Bellewood Golf Club (C), and Royal Oaks Golf Course (D). Means followed by the same letter are not different according to Fisher's protected least significant difference test at $P \leq 0.05$. Dollar spot levels in untreated plots are shown for comparison proposes but are not included in the statistical analysis.

provided improved suppression when compared with flat-fan nozzles that produce extremely coarse droplets (Shepard et al., 2006; Wolf et al., 2002). 
In years where dollar spot pressure is low, the impact of nozzle type on disease control may not be observed. During periods of high dollar spot pressure, however, the impact of nozzle likely plays a larger role in the suppression of the disease. Based on the seasonal AUDPC values of sites evaluated in this study, dollar spot occurred in three distinct epidemics. At SGC, disease incidence was severe and the greatest suppression of dollar spot was provided by XR11003, XR11004, and AI11004 nozzles (Fig. 1). At CCF and $\mathrm{BGC}$, dollar spot pressure was low and no differences were observed among nozzle types. Under moderate pressure observed at ROGC, all nozzles producing droplet sizes in the range of fine to very coarse reduced AUDPC when compared with the nozzle producing the largest droplets (i.e., 1/4TTJ04). To achieve maximum dollar spot control, nozzle types that produce fine to coarse droplet sizes will provide the greatest level of suppression. Additionally, excellent disease and drift management may occur by selecting nozzles that incorporate improved technology such as air induction. This information may be useful for managing dollar spot and potentially other foliar diseases, but its usefulness on root- and crown-inhabiting pathogens remains unclear. In an effort to improve fungicide efficacy and to reduce environmental and economic costs, future research should continue to evaluate the impact of nozzle type and application techniques.

\section{Literature Cited}

Agnew, M. and M. Fidanza. 2007. A manageable process. Golf Course Industry 19:88-90, 94.

Agnew, M.L. 2007. Building disease control programs on annual bluegrass greens in the midAtlantic region. Golf Course Mgt. 75:91-97.

Armstrong-Cho, C., G. Chongo, T. Wolf, T. Hogg, E. Johnson, and S. Banniza. 2008. The effect of spray quality on ascochyta blight control in chickpea. Crop Prot. 27:700-709.

Campbell, C.L. and L.V. Madden. 1990. Introduction to plant disease epidemiology. John Wiley and Sons, New York.

Chapple, A.C., T.M. Wolf, R.A. Downer, R.A.J. Taylor, and F.R. Hall. 1997. Use of nozzleinduced air-entrainment to reduce active ingredient requirements for pest control. Crop Prot. 16:323-330.

Couch, H.B. 1985. Turfgrass fungicides II: Dilution rates, nozzle size, nozzle pressure and disease control. Golf Course Mgt. 52:73-76, 78-80.

Couch, H.B. 1995. Diseases of turfgrasses, 3rd ed. Krieger Publishing, Malabar, FL.

Dernoeden, P.H. 2000. Creeping bentgrass management: Summer stresses, weeds and selected maladies. Ann Arbor Press, Chelsea, MI.

Doney, J.C. and P. Vincelli. 1994. Control of Sclerotinia homoeocarpa with reduced sensitivity to DMI fungicides on two greens, 1993. Fungicide Nematicide Tests 49:327.

Fidanza, M.A., B.B. Clarke, M.L. Agnew, J.E. Kaminski, and T. Reed. 2007. Pesticide application research demonstrated at a field day event. J. Extension 45(1), article \#11AW7.

Fidanza, M.A., H.C. Wetzel, III, M.L. Agnew, and J.E. Kaminski. 2006. Evaluation of fungicide and plant growth regulator tank-mix programmes on dollar spot severity of creeping bentgrass. Crop Prot. 25:1032-1038.

Fidanza, M.A., J.E. Kaminski, M.L. Agnew, and D. Shepard. 2009a. Evaluation of water droplet size and water-carrier volume on fungicide performance for anthracnose control on annual bluegrass. Int. Turfgrass Soc. Res. J. 11:195205.

Fidanza, M.A., J.S. Gregos, B. Aynardi, and D. Hudson. 2009b. Evaluation of fungicides and water-carrier droplet size for dollar spot control in creeping bentgrass, 2006. Plant Dis. Mgt. Rep. (online). Report 3: T064. DOI: 10.1094/ PDMR03. American Phytopathological Society, St. Paul, MN.

Golembiewski, R.C., J.M. Vargas, A.L. Jones, and A.R. Detweiler. 1995. Detection of demethylation inhibitor (DMI) resistance in Sclerotinia homoeocarpa populations. Plant Dis. 79:491493.

Hewitt, A.J., D.L. Valcore, and J.E. Bryant. 1996. Nozzle and application parameter effects on droplet size and use of spray classification schemes. ASAE Paper AA96-003.

Jensen, P.K., L.N. Jorgensen, and E. Kirknel. 2001. Biological efficacy of herbicides and fungicides applied with low-drift and twin-fluid nozzles. Crop Prot. 20:57-64.

Kaminski, J.E., M.A. Fidanza, M. Agnew, and J. Gregos. 2006. Impact of nozzle type on dollar spot control. Phtyopathology (Abstract) 96:S58.

Lesnik, M., C. Pintar, A. Lobnik, and M. Kolar. 2005. Comparison of the effectiveness of standard and drift-reducing nozzles for control of some pests of apple. Crop Prot. 24:93-100.

Matthews, G.A. 1999. Application of pesticides to crops. Imperial College Press, London.

Mead, R., R.N. Curnow, and A.M. Hasted. 2003. Statistical methods in agriculture and experimental biology, 3rd ed. CRC Press, Boca Raton, FL.

Shepard, D., M. Agnew, M. Fidanza, J. Kaminski, and L. Dant. 2006. Selecting nozzles for fungicide spray applications. Golf Course Mgt. 74:83-88.

Smiley, R.W., P.H. Dernoeden, and B.B. Clarke. 2005. Compendium of turfgrass diseases. 3rd ed. American Phytopathological Society, St. Paul, MN.

Vincelli, P. and E. Dixon. 2007. Does spray coverage influence fungicide efficacy against dollar spot? Applied Turfgrass Sci. DOI: 10.1094/ATS-2007-1218-01-RS.

Watschke, T.L., P.H. Dernoeden, and D.J. Shetlar. 1994. Managing turfgrass pests. CRC Press, Boca Raton, FL.

Wolf, R.E., D.R. Gardisser, J. Slocombe, and B.W. Shaw. 2002. Nozzle types for boom sprayer applications of crop protection products. Publication MF-2541, Kansas State University Agricultural Experiment Station and Cooperative Extension Service, Manhattan, KS.

Zontek, S.J. 2003. Strategies from the field to delay fungal resistance. USGA Green Section Record 47:24-27. 